\title{
On the Construction of Internet Traffic Billing System
}

\author{
Chunyan Lei \\ School of Media Studies \& Humanities \\ Zhejiang University City College \\ Hangzhou, China \\ 277197780@qq.com
}

\author{
Bin Huang \\ School of Media Studies \& Humanities \\ Zhejiang University City College \\ Hangzhou, China \\ huangbin@zucc.edu.com
}

\begin{abstract}
Mobile internet as one operating system has already become very mature. But traffic billing is a hot issue among mobile complaints currently. In order to adjust the instability of mobile traffic billing system, adjustment is being made on multiple aspects of the stability to solve the problem of the variable billing system. The internet traffic billing system is stabilized through the establishment of mobile internet traffic billing system, system of mobile internet traffic accumulation and mobile internet identification system, while combining with system of reminding with text messages of mobile phone. In order to carry out the executive process, take for example the cases of the internet traffic billing system of two major communication operators in China. Analysis on the examples showed that with multiple subsystems' assistance, internet traffic billing system can make more accurate calculation and system of monitoring mobile Internet will monitor the use of traffic and provide the most stable methods of billing internet traffic. The combination of multiple systems can better eliminate the errors caused by the instability of the mobile internet traffic billing system.
\end{abstract}

Keywords-Traffic; billing system; monitoring; data Introduction

* Chunyan Lei is the first author; Bin Huang is the correspondence author

The mobile internet has become one of the main channels of accessing to external information, and more people choose handheld type to browse information. Because the related coverage of information is becoming broader and broader, the interests are related to higher extent; the requirements for data accuracy of audience is higher and higher, it is very necessary to establish internet traffic billing system that is accurate, safe and userfriendly so that the stable traffic billing system can provide the accurate process of traffic usage more stably.

\section{Mobile Internet Users And Ways To Use The INTERNET}

\section{A. Mobile Internet Users}

With an increase in the number of phone users and progress of Internet era, more people tend to use mobile internet. The phone that supports web browser connects with the Internet via WAP protocol so that people can surf the Internet, which makes it easy for people to learn, shop and know what is happening outside. The 30th Statistical
Report on Internet Development released by CNNIC showed that the number of mobile phone users in China has reached 380 million, exceeding PC Internet users for the first time. As of June 2011, the mobile Internet users has reached 0.31768 billion.

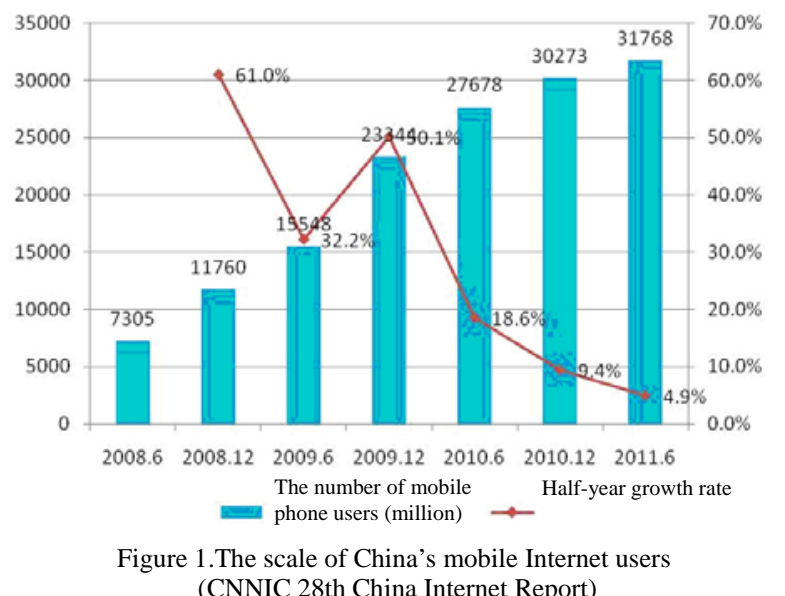

B. Ways To Use Mobile Traffic

Currently, there are several ways of mobile Internet - CmWAP (China Mobile Wireless Application Protocol): So far, China Mobile's WAP gateway external is only HTTP (hypertext transport protocol). - Cmnet (China Mobile Net): Cmnet has full access to Internet, and to the port without any restrictions; the speed is relatively fast and stable.

- Monternet Agent - it is another name for CmWAP. It is accessible to the Internet through limited networking.

- WiFi (Wireless Fidelity) wireless network: Along with the phone hardware upgrading, now China's high-end smart phones have been able to connect via WiFi Internet.

- CDMA (Code Division Multiple Access) applies to Unicom's CDMA network phone with relatively closed environment and faster speed.

\section{Billing For Mobile INTERNET TrAFFIC}

\section{A. Users Of Mobile Operators}

After a survey in 2012 of the number of users, revenue and growth rate of the world's leading operators, Wireless Intelligence released a report showing that China Mobile was still the world's largest mobile operator. 
These data and information was acquired in the second season. It is reported that, as of the previous quarter, China Mobile has 1.02 billion users; followed by China Unicom with 70.067 million users. To make persuasive, Unicom and China Mobile were taken as the examples as followings.

\section{B. Internet Traffic Charges}

TABLE I. THE CHARGES

\begin{tabular}{|c|c|c|c|c|}
\hline $\begin{array}{l}\text { Package } \\
\text { name }\end{array}$ & $\begin{array}{c}\text { Monthl } \\
\text { y fee }\end{array}$ & $\begin{array}{l}\text { Monthly traffic } \\
\text { (Including traffic } \\
\text { on the T \& G } \\
\text { network) }\end{array}$ & Excess & $\begin{array}{l}\text { Monthly } \\
\text { cap fee }\end{array}$ \\
\hline $\begin{array}{c}\text { Standard } \\
\text { charge }\end{array}$ & 0 RMB & 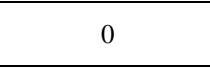 & \multirow{6}{*}{$\begin{array}{l}0.01 \mathrm{R} \\
\mathrm{MB} / \mathrm{K} \\
\mathrm{B}\end{array}$} & \multirow{6}{*}{$\begin{array}{l}1000 \\
\mathrm{RMB}\end{array}$} \\
\hline $\begin{array}{c}5 \text { RMB } \\
\text { Package }\end{array}$ & $5 \mathrm{RMB}$ & $30 \mathrm{M}$ & & \\
\hline $\begin{array}{l}20 \text { RMB } \\
\text { Package }\end{array}$ & $20 \mathrm{RMB}$ & $150 \mathrm{M}$ & & \\
\hline $\begin{array}{l}50 \text { RMB } \\
\text { Package }\end{array}$ & $50 \mathrm{RMB}$ & $500 \mathrm{M}$ & & \\
\hline $\begin{array}{c}100 \text { RMB } \\
\text { Package }\end{array}$ & $\begin{array}{c}100 \\
\text { RMB }\end{array}$ & $2 \mathrm{G}$ & & \\
\hline $\begin{array}{c}200 \text { RMB } \\
\text { Package }\end{array}$ & $\begin{array}{c}200 \\
\text { RMB }\end{array}$ & $5 G$ & & \\
\hline
\end{tabular}

If the traffic flow of China Unicom exceeds the limit, the overstepping portion will charge 0.1 RMB / MB, while in the same case, for China mobile, it will charge $0.01 \mathrm{RMB} / \mathrm{MB}$. But the fact is that different from timing system or monthly subscription system commonly used by the fixed-line broadband Internet, mobile phone uses mobile network to surf the Internet

The traffic packages used as a billing method contain certain traffic flow. If exceeding it, $0.01 \mathrm{RMB}$ will be charged for $1 \mathrm{~KB}$ by China mobile. The more you exceed it, the higher the charge will be.

Entering "complaints of China mobile charges for exceeding traffic limit” on Google, there are 7,680,000 search result; entering "complaints of Unicom charges for exceeding traffic limit, there are 3,570,000 search results. These data can't directly reflect some of the problems, but it can be seen that users of the two communications giants hold complaints for the charges of exceeding Internet traffic limit, which shows that the billing system for mobile Internet traffic is unstable and immature.

\section{PRoblems Of TRAfFic Billing System}

\section{A. Fairness}

The There are some shortcomings in use of the Internet traffic. Take China Mobile for example: the monthly Internet traffic in packages is $50 \mathrm{M}$. If $50 \mathrm{M}$ runs out, users will be charged for the overstep portion. If only $15 \mathrm{M}$ is used in this month, the rest of $35 \mathrm{M}$ will be recovered by China Mobile and there are only 50M for next month because 35M last month cannot be accumulated to the next month. That shows that the traffic is "lost" that is bought with the user's money. It is the same with the case that people are not allowed to take away their own leftovers, which is detrimental to the interests of consumers, and indirectly will lead to the user's dissatisfaction and loss of trust.

\section{B. Accuracy}

Another problem is if the call and message charges run out, the phone cannot call again and receive messages. When Internet traffic is used up, the phone still can normally surf the Internet, which makes a lot of people charged for much money without knowing that they have exceed the traffic limit. Entering "no reminders from China Mobile or Unicom for exceeding the traffic limit" on Google, there are 744,000 pieces of information.

It is not without reminder but delay statistics of traffic data. People receive the reminder that traffic will soon exceed package limit and immediately turn off the mobile Internet, the query of the bill still shows that $166 \mathrm{M}$ is exceeded. It is a possibility of delay statistics of traffic data $s$ in the current system.

\section{Standard Ability}

If the traffic flow of China Unicom exceeds, the overstep portion will charge 0.1 RMB / MB, while in the same case, for China mobile, it will charge 0.01 RMB / $\mathrm{MB}$. But the fact is that different from timing system or monthly subscription system commonly used by the fixedline broadband Internet, mobile phone uses mobile network to surf the Internet. The traffic packages used as a billing method contain certain traffic flow. If exceeding it, $0.01 \mathrm{RMB}$ will be charged for $1 \mathrm{~KB}$ by China mobile. The more you exceed it, the higher the charge will be. Entering " complaints of China mobile charges for exceeding traffic limit" on Google, there are 7,680,000 search result; entering "complaints of Unicom charges for exceeding traffic limit, there are 3,570,000 search results. These data can't directly reflect some of the problems, but it can be seen that users of the two communications giants hold complaints for the charges of exceeding Internet traffic limit, which shows that the billing system for mobile Internet traffic is unstable and immature.

\section{Security}

Sometimes inexplicable loss of traffic is one of the biggest security risks caused by the system vulnerability. Many users have suffered a loss of tens of megabytes or even several hundreds of megabytes to several gigabytes .It makes them pay a few hundred RMB a night even when their phone isn't in operation, and no internet program is opened. This is about the security problems of the Internet account and password easily stolen, which makes the user pay for others' usage of Internet traffic. In addition, phone Trojans and viruses will cause traffic loss. The malware of "Andrews money sucker" intercepted in 2011 was plaguing more than 100 software. Once the user inadvertently downloads it to the phone, nasty software opens the root permission to make background networking software to download software for promotion of malware while consuming the user's Internet traffic.

\section{IMPROVEMENT OF TRAFFIC BILLING SYSTEM}


The following pieces of suggestion for the establishment and improvement of traffic billing system are based on the real-name system. It is because when there are relatively large amount of arrears payment, most of users may feel that it is cheaper to change different number, which not only interferes with the implementation of the following system but also is unfair to other customers. The real-name system identification only accepts one card with one identity card. If some customers need more than one card, they will be audited in some way, which ensuring the interests of the customers and the company more comprehensively.

But some people reject real-name system. It is also not enforceable but carried out voluntarily. So the one with real name system will have more terminal protection.

\section{A. Establish Traffic Measurement System}

- Accumulative return

Each user has its own monthly traffic which is not average. It is necessary to establish system of traffic accumulation and each user has its own independent traffic measurement system. The traffic that hasn't been used will be accumulated to the next month, actually equivalent to system of call billing that if call fees haven't run out, they can be accumulated to the next month rather than be cleared off every month. The traffic is paid by the users so that they have the right to handle it.

\section{- Usage amount billing}

Another way is billing based on usage amount of traffic. In addition to traffic billing and timing billing, the internet billing systems also include charter billing. Mobile Internet traffic billing is the most fair and reasonable as it is related to the issue of cost, the factor affecting pricing most directly. The data business is mostly about services of storage and forward business. In terms of non-real-time data traffic, the cost depends on the amount of information transmitted rather than time of connecting to internet.

It should be required to develop standardized approach of the remaining traffic to improve Internet traffic billing system. To achieve customer satisfaction, it is necessary to create users' record of usage amount of traffic and online measurement system. That is recording the remaining traffic of each user at the end of each month, which can then be accumulated to the next month, or be charged based on usage amount of traffic.

\section{B. Establish Traffic Measurement System}

10086 is hotline of China Mobile and 10010 is of China Unicom for users to check balance inquiries, bill, services being used and consumption point, and giving reminder when calls balance is less than $10 \mathrm{RMB}$. These services are very user-friendly. It is also very necessary to establish similar reminder when Internet traffic is not enough. Users are relatively high charged if they exceed the traffic limit and usually the loss of traffic is relatively fast. So it is difficult to remind at once. So a traffic monitor can be developed by China Mobile or China
Unicom and installed on the phone. Actually this software already exists but is not popular. It can be promoted by China Mobile and China Unicom. It is preferable if the phone card comes with this function, or China Mobile or China Unicom offer terminal reminder.

\section{Standardize Traffic Billing Methods}

China Mobile and Unicom have proposed the traffic billing methods. But it is necessary to build a more thorough traffic calculation method. For example, how to calculate the expense if the traffic of browsing a web page is less than $1 \mathrm{~kb}$ ? Is it cumulative or counted as $1 \mathrm{~kb}$. A billing method considering about un-exceeded traffic should be set up.

\section{Establish A Secure Identification System}

Creating a traffic security guarantee requires good monitoring system. For example, there is online consumer protection when shopping online on Taobao. Users' accounts will not be seen or stolen by others.

The users should be careful themselves. But the mobile operators can use the security identification to ensure the security of the system by ensuring that the network opened by one number can only be used by this number and not be used if another phone number uses the network. Although entering the password for each login is very troublesome, keeping in mind the password is not a good thing. Even if sometimes only with signals, the phone will be automatically connected to internet and then unknowingly cause traffic flow. Therefore, verification code and entering the password for each login is a good way to protect account security.

\section{E. Process Of Internet Traffic Billing}

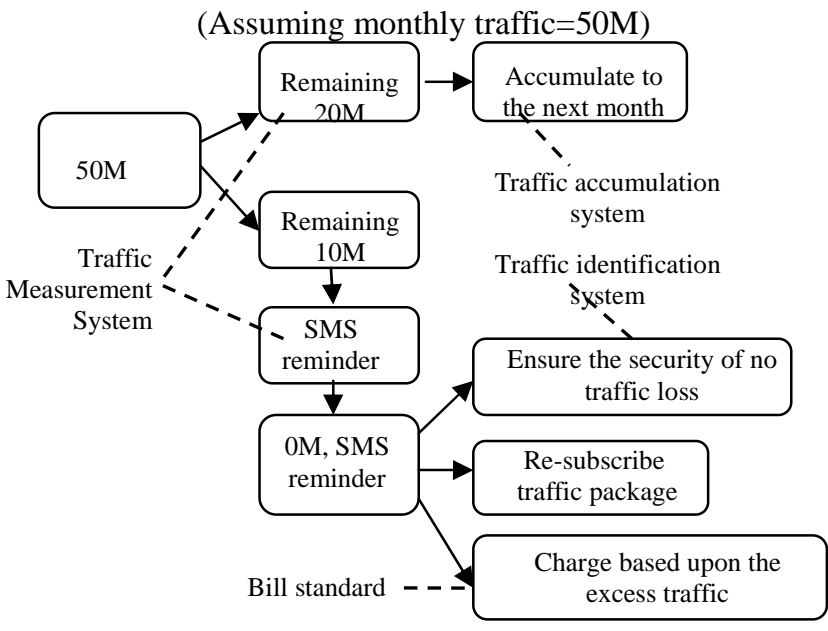

Figure2.Process of internet traffic billing .

And on the basis above, login password at every access helps to reduce the security risks.

It can be seen from the graph that to complete the construction of Internet traffic billing system, following steps are required: 
- SMS system reminds online timely of traffic usage amount.

- Traffic security system ensures that the traffic will not be lost without cause.

- The billing system for extra traffic is fair and stable.

\section{CONCLUSION}

Improving Internet traffic billing system is of positive significances for the communications industry and the interests of Internet users. It can make channels of sharing information opener and charges more standard. This paper aims at improving the Internet traffic billing system so as to provide mobile Internet users with a better experience by following the principle of user-orientation and upgrading system by mobile operators as well as a safe and relieving Internet environment in which users don't need to worry about traffic loss or account stealing or money loss caused by using mobile traffic unknowingly.

\section{REFERENCES}

[1] L.F. WANG, "Design and implementation of Internet traffic billing system based on promiscuous mode.," Computer Learning, 2009

[2] H. Li, "Dynamic query of campus internet traffic billing," Zhanjiang Normal College, 2002

[3] L. XU, "Duration charges should have uniform criteria,” Mobile Communications, 2009

[4] Q. Lei, "Mobile Internet: be alert to black hole of traffic," China New Communications, Dec.2011

[5] F.B. XU, Unclear charges of mobile internet traffic. On People's Well-being.

[6] L. Wang, Y.J. Zhao, "Analysis of program of monitoring unhealthy mobile Internet information,” Data Communication, 2011.pp.70. 